\title{
RELATIONSHIP BETWEEN PATHOLOGICAL MENSTRUAL SYMPTOMS AND THE DEVELOPMENT OF EXTRAGENITAL FORMS OF LOCAL INFLAMMATION
}

10.36740/WLek202101112

\author{
Larysa M. Malanchuk, Mariia 0. Riabokon, Artem S. Malanchuk, Svitlana S. Riabokon, Serhiy L. Malanchuk, \\ Viktoriia M. Martyniuk, Tetiana A. Grabchak, Inna B. Pitsyk \\ I. HORBACHEVSKY TERNOPIL NATIONAL MEDICAL UNIVERSITY, TERNOPIL, UKRAINE
}

\begin{abstract}
The aim: To evaluate the parameters of menstrual function in 1015 women of reproductive age and to establish the relationship between the detected menstrual disorders and the development of migraine and/or irritable bowel syndrome (IBS).

Materials and methods: During 2018-2020, a survey of women of reproductive age in the Ternopil region (Ukraine) was conducted. To interview the study respondents, we developed a questionnaire that assessed the parameters of menstrual function (age of menarche; regularity and cyclicity of menstrual changes; duration of the menstrual cycle and menstruation itself; the amount of blood loss with the pictogram, the presence of clots and their size) identify characteristic changes in health, symptoms of irritable bowel syndrome and migraine associated with the menstrual cycle. Data analysis was performed by statistical and mathematical method.

Results and conclusions: In $72.2 \%$ of respondents, the study revealed deviations from the normal course of the menstrual cycle. In particular, an increase in blood loss during menstruation and the appearance of clots larger than $1 \mathrm{~cm}$ were observed in $40.8 \%$ of women. Among patients with menstrual dysfunction, $51.8 \%$ of patients had symptoms of irritable bowel syndrome, and $44.1 \%$ had signs of migraine.

Thus, the relationship between cyclic menstrual disorders and the formation of IBS and migraine, which significantly affects the deterioration of health, performance of women of childbearing age.
\end{abstract}

KEY WORDS: menstrual cycle and its features, menstrual inflammation, irritable bowel syndrome (IBS), migraine disorders, women of reproductive age

Wiad Lek. 2021;74(1):64-67

\section{INTRODUCTION}

In recent years, in the modern medical literature there are frequent data on the relationship between disorders of endometrial regeneration in menstrual cycles and the emergence of inflammatory symptoms in organs with genetically determined or acquired sensitivity to monthly hormonal and immunological changes in the reproductive organs $[1,2]$.

In particular, the study by Bertone-Johnson E.R., Ronnenberg A.G., Houghton S.C., et al. [3], in patients of reproductive age with manifestations of premenstrual syndrome (PMS) there were pronounced fluctuations in the concentrations of key inflammatory mediators (cytokines - interleukins of the types 8,6 and 4; matrix metalloproteinase-1; cyclooxygenase-2, prostaglandins PGE2 and PGF2 $\alpha$, histamine, serotonin, bradykinin, tumor necrosis factor- $\alpha$ ) during the cycle compared with women without PMS $[4,5]$.

According to the works of Heitkemper M.M. et al. and Berbic M., Ng C.H.M., Fraser I.S., who studied immunological changes in patients with normal menstrual function, menstrual inflammation should be considered as a physiological process that occurs in response to interactions between the endocrine and immune systems [6-8]. However, the appearance of symptoms of local and systemic inflammation in the non-reproductive organs and systems associated with menstruation is the result of a violation of the latter $[9,10,11]$.

Thus, further study of the features of the menstrual cycle as a predictor of the development of pathological disorders in organs and systems genetically sensitive to cyclical changes in the body of a woman is relevant.

\section{THE AIM}

The aim of the study was to evaluate the parameters of menstrual function in 1015 women of reproductive age and to establish the relationship between the detected menstrual disorders and the development of migraine and/ or irritable bowel syndrome.

\section{MATERIALS AND METHODS}

The study was conducted on the basis of the Ternopil Regional Clinical Perinatal Center "Mother and Child", which is the clinical base of the Department of Obstetrics and Gynecology No. 1, Medical Faculty of Ternopil National Medical University. 


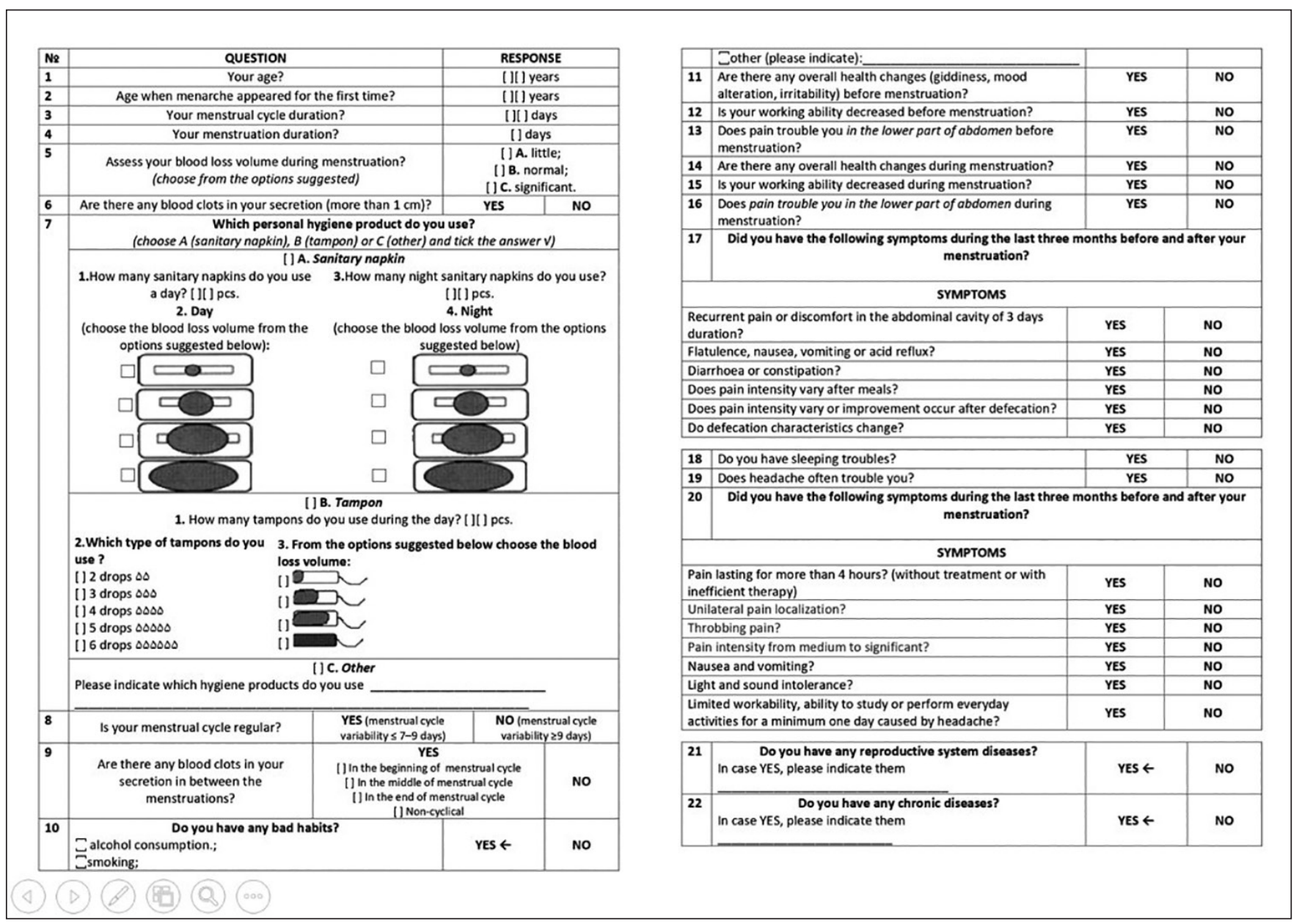

Fig. 1. Sample questionnaire.

\begin{tabular}{|c|c|c|c|}
\hline Parameter & Normal & Abnormal & 田 \\
\hline \multirow{4}{*}{ Frequency } & \multicolumn{2}{|c|}{ Absent (no bleeding) = amenorrhea } & $\square$ \\
\hline & \multicolumn{2}{|c|}{ Infrequent (>38 days) } & $\square$ \\
\hline & \multicolumn{2}{|l|}{ Normal ( $\geq 24$ to $\leq 38$ days) } & $\square$ \\
\hline & \multicolumn{2}{|l|}{ Frequent (<24 days) } & $\square$ \\
\hline \multirow{2}{*}{ Duration } & \multicolumn{2}{|l|}{ Normal ( $\leq 8$ days) } & $\square$ \\
\hline & \multicolumn{2}{|l|}{ Prolonged ( $>8$ days) } & $\square$ \\
\hline \multirow{2}{*}{ Regularity } & \multicolumn{2}{|c|}{ Normal or "Regular" (shortest to longest cycle variation: $\leq 7-9$ days)* } & $\square$ \\
\hline & \multicolumn{2}{|c|}{ Irregular (shortest to longest cycle variation: $\geq 8-10$ days)* } & $\square$ \\
\hline \multirow{3}{*}{$\begin{array}{c}\text { Flow Volume } \\
\text { (patient determined) }\end{array}$} & \multicolumn{2}{|c|}{ Light } & $\square$ \\
\hline & \multicolumn{2}{|l|}{ Normal } & $\square$ \\
\hline & \multicolumn{2}{|l|}{ Heavy } & $\square$ \\
\hline \multirow{5}{*}{$\begin{array}{l}\text { Intermenstrual } \\
\text { Bleeding (IMB) } \\
\text { Bleeding between cyclically } \\
\text { regular onset of menses }\end{array}$} & \multicolumn{2}{|l|}{ None } & $\square$ \\
\hline & \multicolumn{2}{|l|}{ Random } & $\square$ \\
\hline & \multirow{3}{*}{ Cyclic (Predictable) } & Early Cycle & $\square$ \\
\hline & & Mid Cycle & $\square$ \\
\hline & & Late Cycle & $\square$ \\
\hline \multirow{3}{*}{$\begin{array}{l}\text { Unscheduled Bleeding } \\
\text { on Progestin } \pm \text { Estrogen } \\
\text { Gonadal Steroids } \\
\text { (birth control pills, rings, } \\
\text { patches or injections) }\end{array}$} & \multicolumn{2}{|c|}{ Not Applicable (not on gonadal steroid medication) } & $\square$ \\
\hline & \multicolumn{2}{|c|}{ None (on gonadal steroid medication) } & $\square$ \\
\hline & \multicolumn{2}{|l|}{ Present } & $\square$ \\
\hline
\end{tabular}

Fig. 2. System for determining the parameters of normal menstrual blood loss (FIGO, 2018) [10]. 
In the period from 2018 to 2020,1015 women were interviewed. The mean age of patients was $(25.2 \pm 7.3)$ years.

To survey the respondents, we developed a questionnaire, which consisted of four blocks of questions. The first block was devoted to assessing the parameters of the menstrual cycle: the time of menarche, regularity and cyclicity, the duration of the cycle and menstruation itself, determining the amount of blood loss, taking into account the amount of hygiene products used day and night and the presence of clots. The presence of bad habits was assessed by question No. 10; changes in health and performance before and during menstruation - questions No. 11-16. The answers of the third and fourth blocks revealed symptoms of irritable bowel syndrome and migraine according to the recommendations of Roman criteria IV and the International Headache Society (Fig. 1) [12, 13, 14].

The assessment of menstrual cycle parameters was performed according to the updated in 2018 international guidelines (clinical guidelines of the National Institute of Health and Quality of Health Care of the United Kingdom (NICE) and the International Federation of Obstetricians and Gynecologists (FIGO)) (Fig. 2) [15]. Severe menstrual bleeding is considered an indicator of menstrual blood loss $80 \mathrm{ml}$ (Clinical protocol for the management of patients with abnormal uterine bleeding, implemented in accordance with the order of the Ministry of Health of Ukraine of April 13, 2016 No. 353) [16].

For the reliability of the evaluation of the obtained data, the study group did not include patients who regularly (for more than 1 month) taking hormonal contraception and women with tumors and inflammatory diseases of the pelvic organs.

Statistical data processing was performed using Microsoft Excel and STATISTICA 12 software.

\section{RESULTS}

According to the questionnaire data, in $91.7 \%$ of cases (931 patients) there was a normal duration of the menstrual cycle. A decrease of $<24$ days was found in 63 women $(6.2 \%)$ (average cycle duration $(20.2 \pm 0.3)$ days), and an increase over 38 days - in 21 (2.1\%) (with an average cycle duration of (47.8 \pm 1.98$)$ days).

Physiological duration of menstruation was diagnosed in 953 study participants, however, 58 women $(5.7 \%)$ indicated a duration of less than 4 days, and $4(0.4 \%)$ more than 8 days.

Analysis of the menstrual blood self-monitoring pictogram showed an increase in blood loss in $40.1 \%$ of patients (407) and a mean volume was $(156.9 \pm 5.33) \mathrm{ml}$.

It was noteworthy that among the cases of increased blood loss in $97.8 \%$ of women there was a normal duration of menstruation, and in $90.9 \%$ - the physiological duration of the menstrual cycle.

Underestimation of blood loss during menstruation in the form of blood clots larger than $1 \mathrm{~cm}$ was found in 188 patients with normal pictogram data, indicating chronic monthly blood loss outside of physiological.
In $75.6 \%$ of respondents the menstrual cycle was regular, $24.4 \%$ - irregular. Intermenstrual bleeding bothered $8.6 \%$ of women.

77 patients reported smoking, 61 - alcohol use, 69 - had both bad habits.

The answers of the participants showed that in most (977 women - 96.3\%) cyclic changes in the body were accompanied by malaise. Most often, patients complained of lower abdominal pain during menstruation, dizziness, mood lability, irritability. These complaints were prevalent in $97.3 \%$ of women with increased blood loss during menstruation according to self-assessment and in $93.1 \%$ of respondents who indicated the presence of clots of $1 \mathrm{~cm}$ or more during menstruation.

In the analysis process of the survey results, $47.9 \%$ (486 women) showed manifestations of irritable bowel syndrome (IBS). Among 6 questions of the questionnaire regarding the diagnostic criteria of IBS (according to Roman Criteria IV), the affirmative answer in most cases concerned complaints about changes in the nature of bowel movements $(63 \%)$ and changes in pain intensity after defecation $(63.6 \%) .212$ patients $(43.6 \%)$ with manifestations of IBS were characterized by complaints of increased menstrual bleeding over $80 \mathrm{ml}$, and $224(46.1 \%)$ - the presence of clots on critical days. The combination of symptoms of IBS with dysmenorrhea was observed in $84.2 \%$ of women, with premenstrual syndrome - in $75.5 \%$.

According to the questionnaire, in $40.3 \%$ of cases (409 women) there were signs of migraine, which were detected in the presence of three positive responses to the questionnaire (recommendations of the International Headache Association). Manifestation of headache symptoms was accompanied by menstrual irregularities: 188 (46\%) women had a blood loss of more than $80 \mathrm{ml} ; 180$ respondents (44\%) of the study indicated the presence of clots larger than $1 \mathrm{~cm}$; in $14(3.4 \%)$ women - the duration of the cycle ranged from more than 38 days, in 27 (6.6\%) - less than 24 days; 22 patients $(5.4 \%)$ indicated a duration of menstruation of less than 4 days, and $9(2.2 \%)$ - more than 8 days; irregular cycle was noted by 292 women $(71.4 \%)$.

In 115 patients with increased blood loss and in 114 cases of blood clots larger than $1 \mathrm{~cm}$ during menstruation, manifestations of IBS and/or migraine were detected.

\section{DISCUSSION}

According to the results of the study, $65.7 \%$ of women of reproductive age had symptoms of IBS and/or migraine: IBS - in 486 women, migraine - in 409, combined pathology - in 228. Against the background of these symptoms, according to personal data, respondents had certain disorders menstrual cycle: in $78.2 \%$ (370 women) with manifestations of IBS and in $79 \%$ (323 patients) - migraines. The most common menstrual cycle disorders in patients with IBS and migraine were associated with changes in menstrual blood volume parameters $(>80 \mathrm{ml})$ and/or the appearance of clots larger than $1 \mathrm{~cm}$ on menstrual days: in IBS -319 cases $(65.6 \%)$, with migraine - 264 (64.5\%), respectively. 
Despite the fact that menstruation is a monthly physiological process of endometrial recovery in non-pregnant women of reproductive age, increasing the duration and intensity of bleeding over time leads to prolongation of local and systemic inflammatory reactions at different levels, which eventually are present in premenstrual syndrome (PMS) to premenstrual magnification.

Given the average age of menarche and the duration of the reproductive period in study respondents and cyclical abnormalities of the menstrual cycle, including increased menstrual blood loss, symptoms of IBS and migraine as manifestations of extragenital local inflammation, may be the result of inadequate restoration of normal cytoarchitecture of endometrial tissue on the background of immunological and hormonal changes.

\section{CONCLUSIONS}

1. The frequency of menstrual disorders among women in the study group was observed in $72.2 \%$. Among the latter, the symptoms of IBS were found in $51.8 \%$, migraines - in $44.1 \%$.

2. Among the menstrual cycle disorders in women with IBS most often there was a change in the parameters of menstrual blood volume $>80 \mathrm{ml}(43.6 \%)$ and the appearance of clots larger than $1 \mathrm{~cm}$ on critical days (46.1\%) and in patients with migraine $-46 \%$ and $44 \%$ respectively.

3. According to the results of the study, cyclic menstrual disorders with a pronounced increase in blood loss during menstruation should be considered as a trigger for the development of IBS and migraine.

4. Given this hypothesis, the management of the diagnosis of IBS and migraine in women of reproductive age should be supplemented by a detailed analysis of menstrual function, and treatment - to include appropriate correction of menstrual cycle disorders.

\section{REFERENCES}

1. Antypkin Y.G., Vdovychenko Y.P., Graziottin A. et al. Uterine bleedings and quality of woman's life. Reprod Endocrinol. 2019;3(47):13-8.

2. Horban N.Y., Vovk I.B., Lysiana T.O. et al. Peculiarities of uterine cavity biocenosis in patients with different types of endometrial hyperproliferative pathology. J Med Life. 2019;12(3):266-70.

3. Bertone-Johnson E.R., Ronnenberg A.G., Houghton S.C. et al. Association of inflammation markers with menstrual symptom severity and premenstrual syndrome in young women. Hum Reprod. 2014;29;9:1987-94.

4. Menzies F.M., Shepherd M.C., Nibbs R.J. et al. The role of mast cells and their mediators in reproduction, pregnancy and labour. Hum Reprod Update. 2011;17.3:383-96.

5. Barbieri R.L. The endocrinology of the menstrual cycle. Method Mol Biol. 2014;1154:145-69.

6. Berbic M., Ng C.H.M., Fraser I.S. Inflammation and endometrial bleeding. Climacteric 2014;2(17):47-53.

7. Heitkemper M.M., Cain K.C., Jarrett M.E. et al. Relationship of bloating to other $\mathrm{Gl}$ and menstrual symptoms in women with irritable bowel syndrome. Dig Dis Sci. 2004;49:88-95.

8. Evans J., Salamonsen L.A. Inflammation, leukocetes and menstruation. Rev Endocr Metab Disor. 2012;13:277-88.
9. Azlan A., Salamonsen L.A., Hutchison J. Endometrial inflammasome activation accompanies menstruation and may have implications for systemic inflammatory events ofthemenstrual cycle. Hum Reprod. 2020;6(35):1363-76.

10. Nikitina I.M., Smiyan S.A., Kondratiuk K.O. et al. Conditions of microelements exchange processes in women's placents in intrauterine infection of the fetus Wiad. Lek., 2020;(7):1434-1438.

11. Martin V.T., Lipton R.B. Epidemiology and biology of menstrual migraine. Headache. 2008;3(48):124-30.

12. Nikitina I.N., Boychuk A.V., Babar T. V. et al. Prediction of threats to multiple pregnancy interruption depending on the cause of its occurrence. Research Journal of Pharmaceutical, Biological and Chemical Sciences. 2016;7(5):764-771.

13. Malanchuk L., Riabokon M., Malanchuk A. et al. The use of data mining techniques for analysis of menstrual cycle parameters and prognosis of migraine symptoms in reproductive age women. Advanced computer information technologies. 2020, p.77-82.

14. Munro M.G., Critchley H.O.D., Fraser I.S. The two FIGO systems for normal and abnormal uterine bleeding symptoms and classification of causes of abnormal uterine bleeding in the reproductive years: 2018 revisions. Int J Gynecol Obstet. 2018;143:393-408.

15. Gorban N.E.,VovkI.B., Nikitina I.M. etal. Immunoglobulin indicators to viruses cytomegal and genital herpes in the blood serum of women with non-atipical endometrial hyperproliferative pathology. Wiad. Lek. 2020;(8):1600-1605.

16. $\mathrm{MoH}$ of Ukraine. Klinichnyi protokol $z$ vedennia patsiientok iz anomalnymy matkovymy krovotechamy, implementovanyi zhidno z nakazom MOZ Ukrainy vid 13.04.2016 r. № 353. [Clinical protocol for the management of patients with abnormal uterine bleeding, implemented in accordance with the Order of the Ministry of Health of Ukraine dated April 13, 2016, No. 353]. (in Ukr.)

\section{ORCID numbers:}

Larysa M. Malanchuk - 0000-0003-0207-3281 A,E,F

Mariia O. Riabokon - 0000-0002-6873-3206 ${ }^{B, E}$

Artem S. Malanchuk - 0000-0001-5470-4722 B,D

Svitlana S. Riabokon - 0000-0002-4413-0582 C,E

Serhiy L. Malanchuk - 0000-0001-5322-9309 D,F

Viktoriia M. Martyniuk - 0000-0002-1108-134X C,E

Tetiana A. Grabchak - 0000-0002-8746-0784 B,E

Inna B. Pitsyk - 0000-0003-4858-479X E,F

\section{Conflict of interest:}

The Authors declare no conflict of interest.

\section{CORRESPONDING AUTHOR Larysa M. Malanchuk}

I. Horbachevsky Ternopil National Medical University

Ternopil, Ukraine

e-mail:malanchuk@tdmu.edu.ua

Received: 11.07 .2020

Accepted: 28.12 .2020

A - Work concept and design, B - Data collection and analysis, C - Responsibility for statistical analysis, D-Writing the article, $\mathbf{E}$-Critical review, $\mathbf{F}$-Final approval of the article 